\title{
Ankle swelling is not always 'medical'
}

\author{
K. H. HAN \& A. K. MAITRA \\ Accident and Emergency Unit, Royal Victoria Infirmary, Newcastle-upon-Tyne, England
}

\section{INTRODUCTION}

In the absence of a history of trauma one generally thinks of a 'medical' cause of ankle swelling. We report a case of distal tibial and fibular stress fractures in which diagnosis was delayed but fortunately with no untoward consequences.

\section{CASE REPORT}

A 65-year-old previously fit and active housewife presented to the accident and emergency department for an acutely painful swollen right ankle. There was no histor of trauma nor recent unusual physical activity. On examination, she could weight bear on the affected side; there was pitting oedema with slight erythema and tenderness over the lateral malleolus. Apart from moderately severe varicose veins in both legs there was no abnormal finding. X-rays of the ankle revealed degenerative changes only. She was discharged home on simple analgesics and advised to rest and elevate the foot and leg.

Two weeks later she returned with worsening symptoms. Repeat X-rays revealed a stress fracture of the lateral malleolus (Fig. 1). She was treated with Viscopaste bandage and elastoplast strapping and partial wear bearing crutches. Piroxicam was started orally. At review 2 weeks later medial malleolar tenderness was noted although the swelling had resolved. X-rays this time showed an additional stress fracture of the distal tibia (Fig. 2). Investigations were carried out to exclude underlying/additional bone pathology and the results were: serum calcium $2.47 \mathrm{mmol} / 1$, serum phosphate $0.92 \mathrm{mmol} / \mathrm{l}$, total protein $71 \mathrm{~g} / \mathrm{l}$, albumin $45 \mathrm{~g} / \mathrm{l}$, alkaline phosphatase $100 \mathrm{u} / \mathrm{l}$, ionized calcium $1.23 \mathrm{mmol} / 1$ ( $\mathrm{pH}$ of serum $7 \cdot 49$ ), plasma parathormone level $0.8 \mathrm{u} / 1$. Serum protein electrophoresis was of a normal pattern. A Tc-99-m-skeletal bone scan showed $\widetilde{\sigma}$ increased uptake in the right ankle.

Corespondence: $\mathrm{Mr}$ K. H. Han, Senior Registrar, Accident and Emergency Unit, Royal Victoria Infirmary, Newcastle-upon-Tyne NE1 4LP, England. 


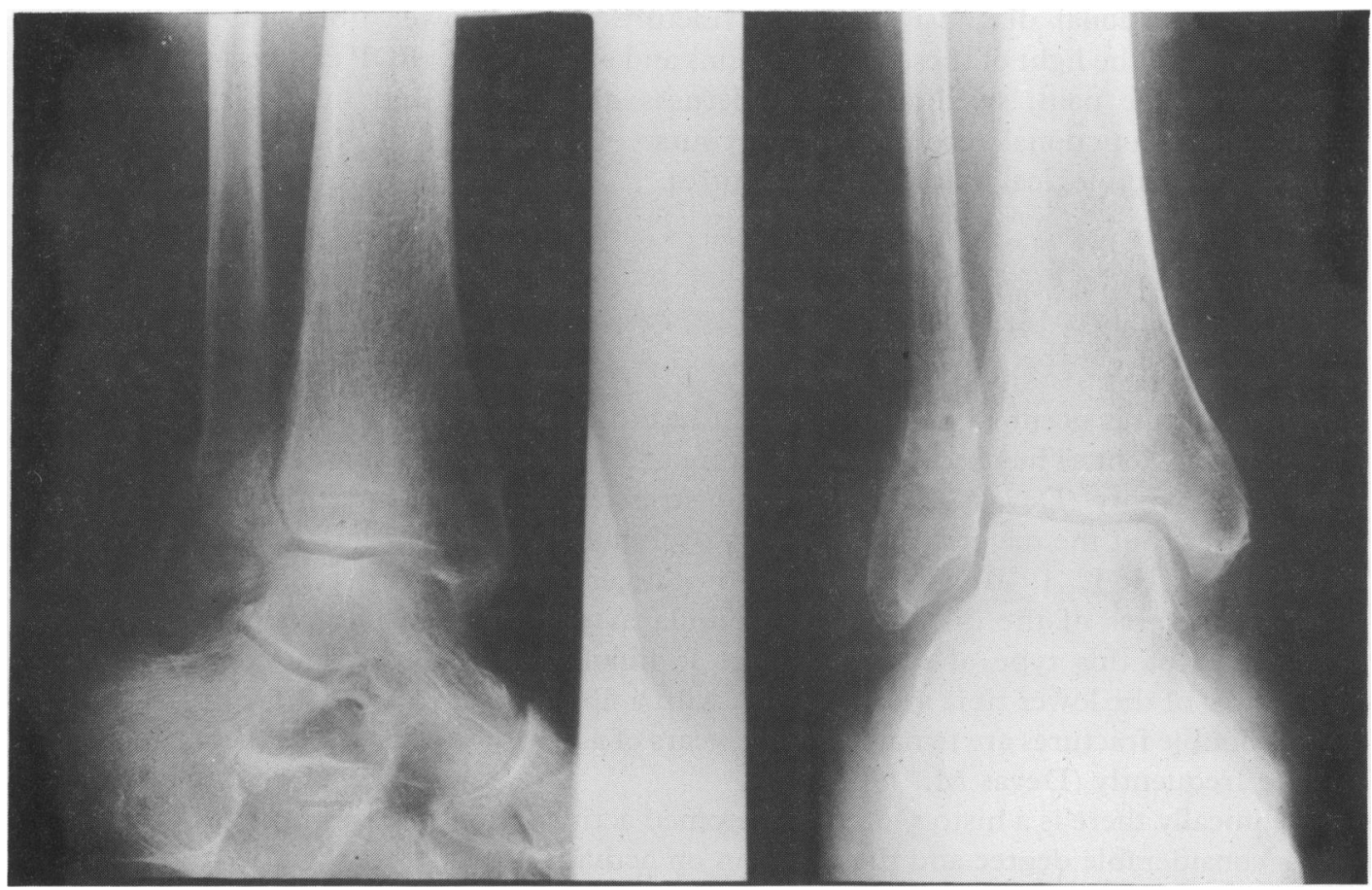

Fig. 1 Stress fracture of right lower fibula.

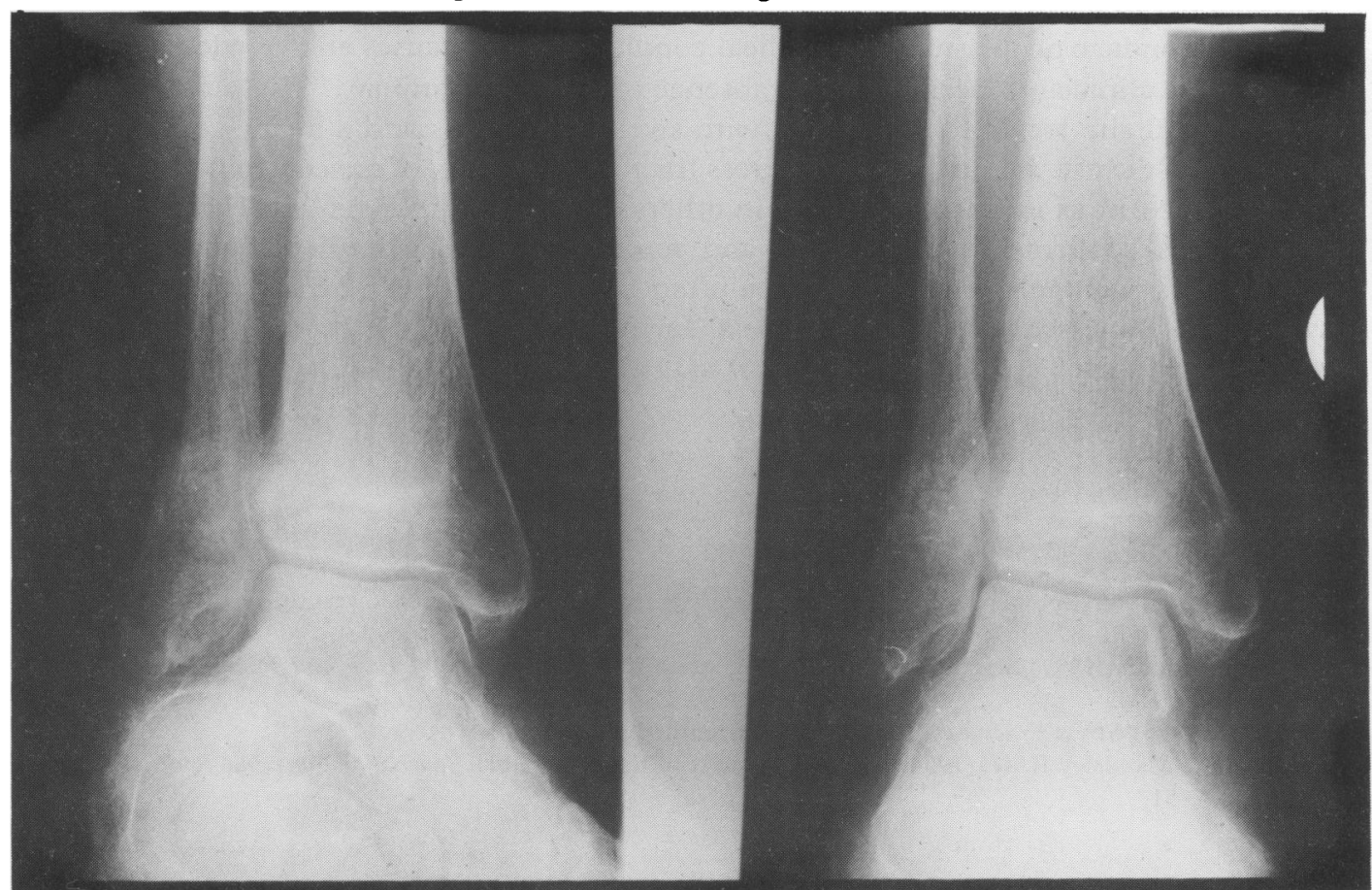

Fig. 2 Subsequent $\mathrm{X}$-rays showing stress fractures of right lower tibia and fibula. 
The provisional diagnosis of stress fractures of the lower tibia and fibula was confirmed in the light of these investigations and a below knee POP cast was applied for 4 weeks. The pain, swelling and tenderness disappeared and the patient made a satisfactory functional recovery after a course of physiotherapy. Subsequent X-rays confirmed radiological union of the fractures.

\section{COMMENT}

Stress fractures occur in normal bones of healthy people, they are not caused by any specific incident. The type of stress fracture and the site at which it occurs varies with age and activity (Devas M. 1975). Some stress fractures are not only disabling but dangerous, but the majority heal with no dysfunction with appropriate treatment.

Burrows H. J. (1940) and subsequently Singer et al. (1954) drew attention to the stress fractures of the distal tibia and fibula in the middle-aged group. The actual incidence of this type of stress fracture is unknown. However, one in four stress fractures of the lower tibia are associated with a fibula fracture and 9 out of 10 patients with double fractures are females over 60 years of age with the distal ends being affected more frequently (Devas M., 1975).

Clinically there is a history of unaccustomed activity in most cases. Ankle swelling is of a considerable degree and there is pain on activity. Usually bony tenderness can be elicited. The differential diagnoses to be considered are: arthritis, osteomyelitiş peripheral vascular disease, varicose veins with coexisting oedema, gout and occasio nally a secondary neoplasm. Any medical condition which causes ankle oedema might mislead the clinician especially in the absence of significant injury.

In general any localized tenderness with swelling, redness and a history of pain on activity must cause the suspicion of a stress fracture. A history of unaccustomed activity might be absent as in this patient and in others described by Singer et al. (1954). The diagnosis is confirmed radiologically and sometimes serial $\mathrm{X}$-rays for 6 weeks are indicated as roentgenographic evidence often lags several weeks behind the onset of symptoms. Bone scans have the potential for demonstrating the lesion(s) earlier and may be used in selected cases (Prather et al. 1977).

\section{REFERENCES}

Burrows H. J. (1940) Spontaneous fracture of the apparently normal fibula in its lowest third. British fournal of Surgery 29, 82-87.

Prather J. L. et al. (1977) Scintigraphic findings in stress fractures. Fournal of Bone and foint Surgery 59A, 869-74.

Devas M. (1975) Stress Fractures. Edinburgh, Churchill Livingstone.

Singer M. \& Maudsley R. H. (1954) Fatigue fractures of the lower tibia. Fournal of Bone and foint Surgery 36B, 647-51. 